\title{
Theoretical Interpretations of the Eliassen-Palm Diagnostics of Wave-Mean Flow Interaction
}

\author{
Part I: Effects of the Lower Boundary
}

\author{
By Yoshikazu Hayashi \\ Geophysical Fluid Dynamics Laboratory/NOAA, Princeton University, P.O. Box 308 \\ Princeton, New Jersey 08542 USA \\ (Manuscript received 19 November 1984, in revised form 17 June 1985)
}

\begin{abstract}
In order to theoretically interpret the Eliassen-Palm diagnostics of wave-mean flow interactions, necessary and sufficient conditions are derived for the Eliassen-Palm flux divergence to approximate the zonal acceleration in the absence of mean damping.

It is shown by a simple analytical model that a violation of these conditions due to the effect of the lower boundary condition may explain why some observational diagnostic studies indicate that transient eddies accelerate westerlies in the mid-latitude upper troposphere in the absence of mean damping, although the transient E-P flux divergence is easterly there.

It is also suggested on the basis of simple diagnostic relations that the steady state upper tropospheric westerlies can be either enhanced or reduced by transient eddies depending on mean damping and radiative heating.
\end{abstract}

\section{Introduction}

It is well known (Eliassen, 1952 ; Phillips, 1954 ; Kuo, 1956) that eddies can not only accelerate zonal mean flows but also can induce mean circulations to maintain geostrophic and hydrostatic balance (see Lorenz, 1967, 1969 for a review of general circulations). In the mid-latitude troposphere, observed eddy momentum and heat fluxes induce an indirect cell (Vernekar, 1967 ; Crawford and Sasamori, 1981 ; Salustri and Stone, 1983). The observed eddy momentum flux convergence dominates the counteracting induced mean Coriolis force and accelerates westerlies in the upper troposphere, while the two effects work in the same direction and accelerate westerlies in the lower troposphere (Wiin-Nielsen and Vernekar, 1967, Pfeffer, 1981). In the absence of dissipation, heating, critical levels or wave transience ("non-acceleration condition"), waves do not accelerate mean flows, although a mean vertical motion is induced by the eddy heat flux (Charney and Drazin, 1961; Holton, 1974; Boyd, 1976; Andrews and McIntyre, 1976, 1978a ; Nakamura, 1979).

In the stratosphere, however, the induced mean Coriolis acceleration plays an important role. For example, in the presence of an instability or wave dissipation, equatorial Rossbygravity waves accelerate easterlies through their dominant induced mean Coriolis acceleration (Hayashi, 1970). These waves may be responsible for the easterly phase of the quasibiennial oscillation (Holton and Lindzen, 1972). In the presence of a wave transience or a critical level, mid-latitude planetary waves can cause a sudden warming due to their heat flux convergence and accelerate easterlies due to their induced mean Coriolis force (Matsuno, 1971).

In order to describe the net efiect of eddies on the zonal flow in a simple manner, Andrews and McIntyre (1976) transformed the Eulerian- 
mean equations in terms of the Eliassen-Palm flux divergence (EPFD) discussed by Eliassen and Palm (1960) and the residual mean circulations $\left(\bar{\psi}^{*}\right)$. This EPFD consists of a combination of eddy momentum and heat flux divergences, while $\bar{\psi}^{*}$ consists of the Eulerianmean circulations and heat fluxes. According to their scale analysis, the residual mean circulations are negligible and the acceleration can be approximated by the EPFD on the "tall mean flow condition." This condition is met when the vertical-lateral scale ratio of the mean acceleration is much larger than $f N^{-1}$, where $f$ and $N$ are the Coriolis and Brunt-Väisälä frequencies, respectively. In the absence of a horizontal shear the vertical component of the EPFD is equivalent to the "effective vertical momentum flux convergence" of Bretherton (1969) and Lindzen (1970). Under quasi-geostrophic scaling the EPFD is equivalent to the quasi-geostrophic eddy potential vorticity flux discussed by Dickinson (1969).

The Eliassen-Palm flux is also a useful measure of wave propagation (Edmon, et al. 1980 ; Palmer, 1982 ; Butchart, et al. 1982) and has been modified to describe local wave propagation (Hoskins, et al. 1983; Plumb, 1985) and to include the effect of eddy forcing of condensational heating (Stone and Salustri, 1984). Also, it has been used to reformulate energy cycle (Plumb, 1983; Kanzawa, 1984a).

Eliassen-Palm diagnostics have been widely applied to observed and simulated planetary waves (e.g., Sato, 1980 ; Edmon, et al. 1980 ; Dunkerton, et al. 1981; Palmer, 1981a, b ; Kanzawa, 1982, 1984b ; O'Neill and Youngblut, 1982 ; Karoly, 1982 ; Andrews, et al. 1983; Geller et al. 1983; Mahlman and Umscheid, 1984; Hartmann et al. 1984). According to Edmon et al. (1980), the observed stationary or transient EPFD indicates easterly mean flow forcing in the midlatitude troposphere except near the surface [see also Wiin-Nielsen and Sela (1977), Pfeffer (1981), Andrews et al. (1983), Geller et al. (1983)]. This easterly forcing appears to be contrary to the net westerly acceleration calculated by WiinNielsen and Vernekar (1967, Fig. 3) and Pfeffer (1981, Fig. 7). However, their calculation is not proper for topographically forced stationary waves, since the lower boundary condition for the Eulerian-mean vertical velocity depends on the topographic height which is neglected. On the other hand, the recent calculation by Lau and Holopainen (1984, Fig. 9) indicates that observed transient eddies accelerate westerlies in the upper troposphere, being consistent with a theoretical study of mixed baroclinic-barotropic instability (Shepherd, 1983, Fig. 6a, Fig. 8). These eddies also accelerate westerlies in the lower troposphere and reduce the mean vertical shear and the latitudinal gradient of the mean temperature in the lower troposphere.

The present paper theoretically interprets the Eliassen-Palm diagnostics of wave-mean flow interaction. Section 2 gives the zonal mean equations, while Section 3 derives conditions for the Eliassen-Palm diagnostics. Section 4 gives a simple analytical model to study the effect the vertical-lateral scale ratio and the boundary conditions, while Section 5 discusses the effect of mean damping. Conclusions and implications are given in Section 6 . Appendix A lists symbols, Appendix B gives the boundary conditions and Appendix $\mathrm{C}$ describes the Green's function.

\section{Zonal-mean equations}

In this section the conventional and transformed Eulerian-mean equations are summarized. The symbols are listed in Appendix A.

\section{a. Zonal-mean equations}

The quasi-geostrophic Eulerian-mean equations on an $f$-plane in the log-pressure coordinates (see Holton, 1975) are simplified by neglecting the nonlinear advection terms and omitting the friction and heating terms as

$$
\begin{aligned}
& \bar{u}_{t}=-M_{y}+f \bar{v}, \\
& \bar{T}_{t}=-B_{y}-R_{H}^{-1} N^{2} \bar{w}, \\
& \left(\rho_{0} \bar{v}\right)_{y}+\left(\rho_{0} \bar{w}\right)_{z}=0, \\
& f \bar{u}_{z}+R_{H} \bar{T}_{y}=0 . \\
& M=\overline{u^{\prime} v^{\prime}}, \\
& B=\overline{T^{\prime} v^{\prime}}, \\
& \rho_{0}=\rho_{s} \exp (-z / H),
\end{aligned}
$$


where the prime denotes a deviation from the zonal mean which is indicated by an overbar. $f$ and $N$ are the Coriolis and Brunt-Väisälä frequencies which are assumed to be constant for simplicity. $H$ is the constant scale factor of the log-pressure coordinate. $R_{H}$ is the gas constant $R$, divided by $H$.

\section{b. Transformed Eulerian-mean equations}

The above Eulerian-mean equations are transformed, following Andrews and McIntyre (1976) as

$$
\begin{aligned}
& \bar{u}_{t}=D+f \bar{v}^{*}, \\
& \bar{T}_{t}=-R_{H}^{-1} N^{2} \bar{w}^{*}, \\
& \left(\rho_{0} \bar{v}^{*}\right)_{y}+\left(\rho_{0} \bar{w}^{*}\right)_{z}=0,
\end{aligned}
$$

and

$$
f \bar{u}_{z}+R_{H} \bar{T}_{y}=0,
$$

where $D$ is the Eliassen-Palm flux divergence and $\left(\bar{v}^{*}, \bar{w}^{*}\right)$ are the residual mean circulations defined by

$$
\begin{aligned}
& D=-M_{y}+f R_{H} N^{-2} \rho_{0}^{-1}\left(\rho_{0} B\right)_{z}, \\
& \bar{v}^{*}=\bar{v}-R_{H} N^{-2} \rho_{0}^{-1}\left(\rho_{0} B\right)_{z},
\end{aligned}
$$

and

$$
\bar{w}^{*}=\bar{w}+R_{H} N^{-2} B_{y} .
$$

When $f \bar{v}^{*}$ in (2.8) is larger than $D$, the tendency is not always of the same sign as $D$. When $\bar{v}^{*}$ in (2.13) is negligible, the second term in (2.12) can be interpreted as approximating $f \bar{v}$ induced by $B$.

In the absence of mean vertical shear and wave heating, the $D$ of steady small amplitude waves approximates the radiation stress divergence, while the residual circulations and the second terms in (2.13) and (2.14) approximate the Lagrangian-mean circulations and the Stokes drift, respectively (Andrews and McIntyre, 1978b; Matsuno and Nakamura, 1979). The radiation stress can be interpreted as a pseudo-momentum flux (Andrews and McIntyre, 1978c ; McIntyre, 1981; Plumb and Bell, 1982). For reviews of Eulerian and Lagrangian-mean circulations, see Uryu (1980), Matsuno, (1980), McIntyre (1980), Dunkerton (1980) and Holton (1980).

\section{Conditions for Eliassen-Palm diagnostics}

In this section, the necessary and sufficient conditions for $D$ to approximate the net eddyinduced acceleration are derived from the elliptic equations.

\section{a. Elliptic equations}

Eliminating variables from the above Eulerian mean equations results in the elliptic equations as

$$
\begin{aligned}
&\left(\bar{u}_{t}\right)_{y y}+f^{2} N^{-2}\left(\bar{u}_{t}\right)_{z H}=D_{y y} \\
&\left(\bar{T}_{t}\right)_{y y}+f^{2} N^{-2}\left(\bar{T}_{t}\right)_{z H}=-f R_{H}^{-1} D_{y z}, \\
&(\bar{\psi})_{y y}+f^{2} N^{-2}(\bar{\psi})_{z H}=-R_{H} N^{-2} B_{y y} \\
&-f N^{-2} M_{y z} \\
&\left(\bar{\psi}^{*}\right)_{y y}+f^{2} N^{-2}\left(\bar{\psi}^{*}\right)_{z H}=f N^{-2} D_{z}
\end{aligned}
$$

where ()$_{z H}$ is defined as

$$
\begin{aligned}
()_{z H} & =()_{z z}-H^{-1}()_{z} \\
& =\rho_{0}^{-1}\left[\rho_{0}()_{z}\right]_{z} .
\end{aligned}
$$

In (3.3), $\rho_{0} \bar{\psi}$ denotes the mass stream function defined by

$$
\left(\rho_{0} \bar{\psi}\right)_{z}=-\rho_{0} \bar{v}
$$

and

$$
\left(\rho_{0} \bar{\psi}\right)_{y}=\rho_{0} \bar{w},
$$

\section{b. Necessary and sufficient conditions}

In the present paper the vertical-latitude scale ratio of $\bar{u}_{t}$ is defined by

$$
r_{u} \equiv\left(\bar{u}_{t}\right)_{y y} /\left(\bar{u}_{t}\right)_{z H} \text {. }
$$

It follows from (3.1) that if and only if

$$
\left|r_{u}\right| \gg f^{2} N^{-2}
$$

then

$$
\left(\bar{u}_{t}\right)_{y y} \approx D_{y y} .
$$

Thus, (3.9) is a diagnostically necessary and sufficient condition ${ }^{1}$ for $\bar{u}_{t} \approx D$.

The condition (3.9) is essentially the same as the "tall mean flow condition" discussed by Andrews and McIntyre (1976) based on the scale analysis of the transformed Eulerian

1 Strictly speaking, (3.9) is a necessary and sufficient condition for (3.10). 
mean equations of a Boussinesq fluid. The present condition is more appropriate for a compressible fluid, since the first $z$ derivative ()$_{z}$ in (3.5a) usually dominates the second $z$ derivative ()$_{z z}$ for stratospheric planetary waves. It should be noted that (3.8) is defined with respect to $\bar{u}_{t}$ rather than $D$. When (3.8) is defined with respect to $D$ as in Andrews et al. (1983, p. 2782), (3.9) is only a necessary condition for $\bar{u}_{t} \approx D$, as discussed below.

It follows from (3.1), that if

$$
\left(\bar{u}_{t}\right)_{y y} \approx D_{y y} \text { and }\left(\bar{u}_{t}\right)_{z H} \approx D_{z H},
$$

then

$$
\left|r_{D}\right| \gg f^{2} N^{-2}
$$

where

$$
r_{D}=D_{y y} / D_{z H} .
$$

Thus, (3.12) is a necessary condition ${ }^{2}$ for $\bar{u}_{t} \approx D$.

It should be noted that if (3.12) holds everywhere, $D$ approximates a particular solution to (3.1). However, $D$ does not approximate $\bar{u}_{t}$ at low levels, since $D$ does not usually satisfy the lower boundary condition.

The solution to (3.1) is also given by the use of the Green's function (see Appendix C). When the condition (3.12) holds, the Green's function behaves like a delta function in the vertical and $\bar{u}_{t}$ is approximated by $D$ for a large $z$.

\section{Analytical model}

In this section a simple analytical model is given to examine the effect of the scale ratio and the lower boundary conditions on wavemean interactions.

\section{a. Analytical solutions}

It is assumed that eddy fluxes due to long and ultralong waves are given by

$$
\begin{aligned}
& \rho_{0} B=B_{0} R_{I I}^{-1} N^{2} \exp (-m z) \sin l y, \\
& \rho_{0} M=M_{0} f \exp (-m z) \cos l y,
\end{aligned}
$$

and

$$
\rho_{0} D=-\left(m B_{0}-l M_{0}\right) f \exp (-m z) \sin l y,
$$

\footnotetext{
"Strictly speaking, (3.12) is a necessary condition for (3.11).
}

where $B_{0}$ and $M_{0}$ are positive constants. It should be noted that $M$ can increase with height, although $\rho_{0} M$ decreases with height.

The vertical-lateral scale ratio of $D$ is given by

$$
r_{D}=-\frac{l^{2}}{m\left(\bar{H}^{-1}-m\right)} .
$$

The lateral boundary condition is given by

$$
\bar{v}=0 \quad \text { at } l y=0 \text { and } \pi \text {. }
$$

Physically reasonable upper and lower boundary conditions are that the Lagrangianmean mass fluxes vanish. In the present solution, these conditions are met by only imposing the following conditions.

The upper boundary condition is given by

$$
\rho_{0} \bar{w}<\infty \text { at } z=\infty .
$$

The lower boundary condition in the absence of topography is given by

$$
\bar{w} \approx 0 \text { at } z=0,
$$

which is equivalent to

$$
\left(\bar{u}_{t}\right)_{2} \approx f^{-1} R_{I I} B_{y y} \text { at } z=0 .
$$

The lower boundary condition (4.7) which is used for observational diagnostics is not exact $(d \phi / d t \neq 0)$. However, this approximation will not seriously affect the upper troposphere. This condition is exact under the non-acceleration condition (see Appendix B).

If the waves are topographically forced in the absence of heating and friction at the surface, the lower boundary condition (see Appendix B) is reduced to

$$
\bar{w} \approx-R_{I I} N^{-2} B_{y} \text { at } z=0,
$$

which is equivalent to

$$
\left(\bar{u}_{t}\right)_{z} \approx 0 \text { at } z=0 \text {. }
$$

The solution to (3.3) in the absence of topography is given by the use of the lower boundary conditions (4.7) and (4.8) as

$$
\rho_{0} \bar{\psi}=-c[\exp (-m z)-\exp (-\mu z)] \sin l y,
$$

and

$$
\begin{aligned}
\bar{u}_{\iota}= & \frac{r_{D}}{r_{D}+f^{2} N^{-\varkappa}} D \\
& +c f \mu \exp \left[-\left(\mu-H^{-1}\right) z\right] \sin l y,
\end{aligned}
$$


while the topographically forced solution is given by the use of the lower boundary conditions (4.9) and (4.10) as

$$
\begin{aligned}
\rho_{0} \bar{\psi}= & {\left[-c \exp (-m z)+\left(c-B_{0}\right)\right.} \\
& \cdot \exp (-\mu z)] \sin l y,
\end{aligned}
$$

and

$$
\begin{aligned}
i i_{t}= & \frac{r_{D}}{r_{D}+f^{2}} \overline{N^{-2}}\left\{D-\left(H^{-1}-m\right)\left(H^{-1}-\mu\right)^{-1}\right. \\
& \left.\cdot D(o) \exp \left[-\left(\mu-H^{-1}\right)\right]\right\} .
\end{aligned}
$$

In the above solutions $c$ and $\mu$ are defined by

$$
c=\frac{B_{0} l^{2}+M_{0} f^{2} N^{-2} l\left(H^{-1}-m\right)}{l^{2}+f^{2} N^{-2} m\left(H^{-1}-m\right)},
$$

and

$$
\begin{aligned}
\mu & =\left[f^{-2} N^{2} l^{2}+(2 H)^{-2}\right]^{1 / 2}+(2 H)^{-1}, \\
& =\left[h_{R}^{-2}+(2 H)^{-2}\right]^{1 / 2}+(2 H)^{-1}, \\
& =\left[-N^{2}(g h)^{-1}+(2 H)^{-2}\right]^{1 / 2}+(2 H)^{-1},
\end{aligned}
$$

$$
h_{R}=f N^{-1} l^{-1},
$$

and

$$
h=-g^{-1} f^{2} l^{-2} .
$$

Here $h_{R}$ is the Rossby depth used in the geostrophic adjustmeent theory, while $h$ is the equivalent depth used in tidal theory. In the present problem this equivalent depth does not depend on the frequency by virtue of the quasi-geostrophic approximation. The negative value of $h$ is consistent with that of zonally symmetric annual oscillations over a sphere discussed by Sawada and Matsushima (1964).

For $m=H^{-1}, B$ and $M$ are constant with height and $\left|r_{D}\right|$ approaches infinity, while $\rho_{0} B$ and $\rho_{0} M$ decay with height. In this case, $M$ does not induce $\bar{\psi}$.

For $0<m<H^{-1}, \rho_{0} B$ and $\rho_{0} M$ decay with height, while $B$ and $M$ increase with height. In this case, both $B$ and $M$ induce an indirect cell $(\bar{\psi}<0)$ for $B_{0}>0$ and $M_{0}>0$.

In the present calculation, it is assumed that $m=0.5 H^{-1}$, since the observed $M$ increases with height in the troposphere. It is also assumed that $m B_{0}=2 l M_{0}$ in (4.3), since the observed $B$ contributes to $D$ at least twice as much as $M$ does. The constants are given below :

$$
\begin{aligned}
& f=10^{-4} \mathrm{~s} \\
& N=10^{-2} \mathrm{~s}^{-1}, \\
& \pi / l=5000 \mathrm{~km} . \\
& H=7 \mathrm{~km}, \\
& m^{-1}=14 \mathrm{~km}, \\
& \mu^{-1}=6 \mathrm{~km}, \\
& h=-2.6 \mathrm{~km},
\end{aligned}
$$

and

$$
h_{R}=16 \mathrm{~km} \text {. }
$$

\section{b. Results}

The conventional and transformed Eulerianmean zonal momentum equations are summarized as

$$
\begin{aligned}
& \bar{u}_{t}=f \bar{v}-M_{y} \\
& \quad=f \bar{v}^{*}+D, \\
& \left(\bar{u}_{t}\right)_{y y}+f^{2} N^{-2}\left(\bar{u}_{t}\right)_{z H}=D_{y y},
\end{aligned}
$$

where

$$
D=f R_{H}^{-2} \rho_{0}^{-1}\left(\rho_{0} B\right)_{z}-M_{y} .
$$

Fig. 1a shows the vertical distributions $(0-$ $10 \mathrm{~km})$ of $\bar{u}_{t}$ and $D$ with the non-topographical boundary condition when both $B$ and $M$, only $B$, and only $M$ are used as forcing functions. The effective value of $N$ is assumed to be $10^{-2} \mathrm{~S}^{-1}$ which is a representative value in the troposphere when the observed lapse rate is taken into account. When both $B$ and $M$ are imposed, it turns out that $D$ is negative (westward acceleration), while $\bar{u}_{t}$ is positive (eastward acceleration) in agreement with some observational diagnostics. The discrepancy between $\bar{u}_{t}$ and $D$ becomes larger when only $B$ is imposed, as compared to that when only $M$ is imposed. When both $B$ and $M$ are imposed, the negative $D$ is primarily due to the effect of $B$, while the positive $\bar{u}_{t}$ is primarily due to the effect of $M$. It should be noted that the effect of $B$ on $\bar{u}_{t}$ is not twice that of $M$, although $B$ contributes to $D$ twice as much as $M$ does. This is because $\bar{u}_{t}$ depends not only on $D$ but also on the surface $B$ through the lower boundary condi- 

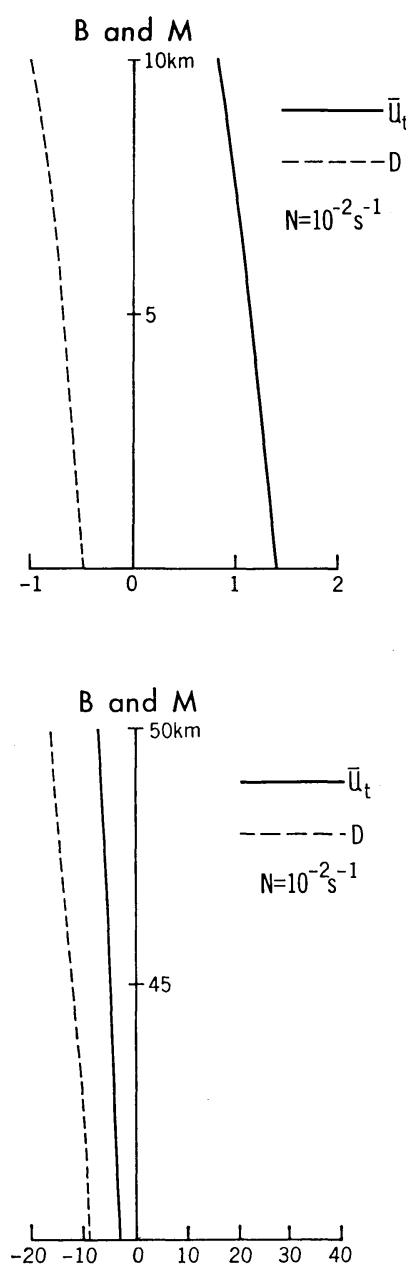
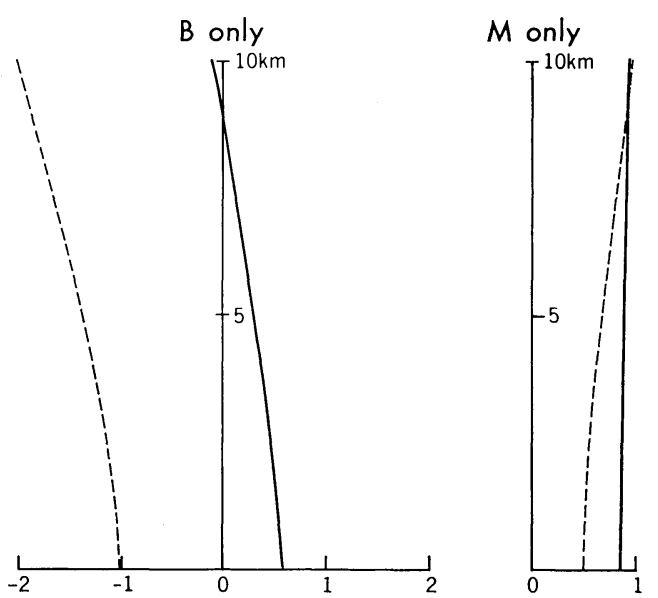

(a)
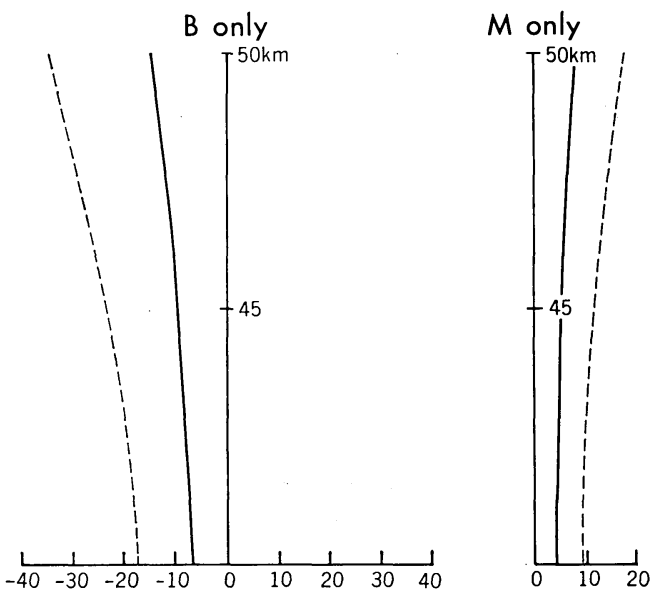

(b)

Fig. 1 Vertical distributions at levels $0-10 \mathrm{~km}$ (a) and $40-50 \mathrm{~km}$ (b) of $u_{t}$ (solid) and $D$ (dashed) for $N=10^{-2} \mathrm{~s}^{-1}$. Forcing with both $B$ and $M$ (left), $B$ only (middle), $M$ only (right). $-M_{y}$ is set to 1 at $10 \mathrm{~km}$.

tion (4.8) in the absence of topography.

Fig. 1b is the same as Fig. 1a except for the levels $40-50 \mathrm{~km}$. At these levels, the effect of the lower boundary is negligible, since it decays with height in (4.12). It is seen that $\bar{u}_{t}$ and $D$ have the same sign for the three cases of forcing and are negative when both $B$ and $M$ are imposed. However, $D$ still overestimates $\bar{u}_{t}$ by a factor of 2.4 . At an infinite height, this factor approaches 2.3 , as is expected from (4.12).

It is of interest to examine the lateralvertical scale ratios defined by (3.8) and (3.13). In this model, $\left|r_{u}\right| \gg f^{2} N^{-2}$ is rigorously a necessary and sufficient condition for $\bar{u}_{t} \approx D$, since $\left(\bar{u}_{t}\right)_{y y}=-l^{2} \bar{u}_{t}$ and $D_{y y}=-l^{2} D$.

For this model, the ratio between $D$ and $\bar{u}_{t}$ is related to $r_{u}$ as

$$
\frac{D}{\bar{u}_{t}}=\frac{1+r_{u} /\left(f^{2} N^{-2}\right)}{r_{u} /\left(f^{2} N^{-2}\right)} \text {. }
$$

This ratio becomes 0 and $\infty$ for $r_{u} /\left(f^{2} N^{-2}\right)$, $=-1$ and 0 , respectively.

Table 1 lists the vertical distribution of the scale ratio of $\bar{u}_{t}$ normalized by $f^{2} N^{-2}$. The normalized scale ratio of $D$ is 0.77 at all the levels for the three cases of forcing. Above $40 \mathrm{~km}, r_{u}$ is close to $r_{D}$. This is due 
Table 1 Vertical distributions of $r_{u} /\left(f^{2} N^{-2}\right)$ for $N=10^{-2} \mathrm{~s}^{-1}$.

\begin{tabular}{ccrr}
\hline$Z(\mathrm{~km})$ & $B$ and $M$ & $B$ only & $M$ only \\
\hline 50 & 0.69 & 0.75 & 0.81 \\
40 & 0.57 & 0.71 & 0.87 \\
30 & 0.32 & 0.61 & 1.05 \\
20 & -0.06 & 0.40 & 1.72 \\
10 & -0.46 & 0.45 & 16.85 \\
\hline 9 & -0.50 & 0.00 & 186.14 \\
8 & -0.53 & -0.04 & -20.85 \\
7 & -0.56 & -0.08 & -9.95 \\
6 & -0.59 & -0.12 & -6.58 \\
5 & -0.62 & -0.16 & -4.95 \\
4 & -0.65 & -0.21 & -3.99 \\
3 & -0.68 & -0.25 & -3.36 \\
2 & -0.70 & -0.29 & -2.91 \\
1 & -0.72 & -0.33 & -2.58 \\
0 & -0.74 & -0.37 & -2.33 \\
\hline
\end{tabular}

to the fact that $\bar{u}_{t}$ and $D$ are nearly proportional at a great height, as expected from (4.12). In the troposphere, $r_{u}$ becomes negative due to the effect of the lower boundary condition. With both $B$ and $M$ and with only $B$, $\left|r_{u}\right| /\left(f^{2} N^{-2}\right)$ is smaller than 1 , being consistent with the fact (Fig. 1a) that $\bar{u}_{t}$ and $D$ are quite different.

Fig. 2 is the same as Fig. 1 except that $N$ is replaced by its representative value $(2 \times$ $\left.10^{-2} \mathrm{~s}^{-1}\right)$ in the stratosphere. It is seen in Fig. 2a $(0-10 \mathrm{~km})$ that $\bar{u}_{t}$ is still positive, although it is somewhat reduced in the upper troposphere when both $B$ and $M$ are used as the forcing. At the $40-50 \mathrm{~km}$ levels (Fig. 2b), $\bar{u}_{t}$ and $D$ are close, their ratio being about 1.3 when both $B$ and $M$ are imposed.
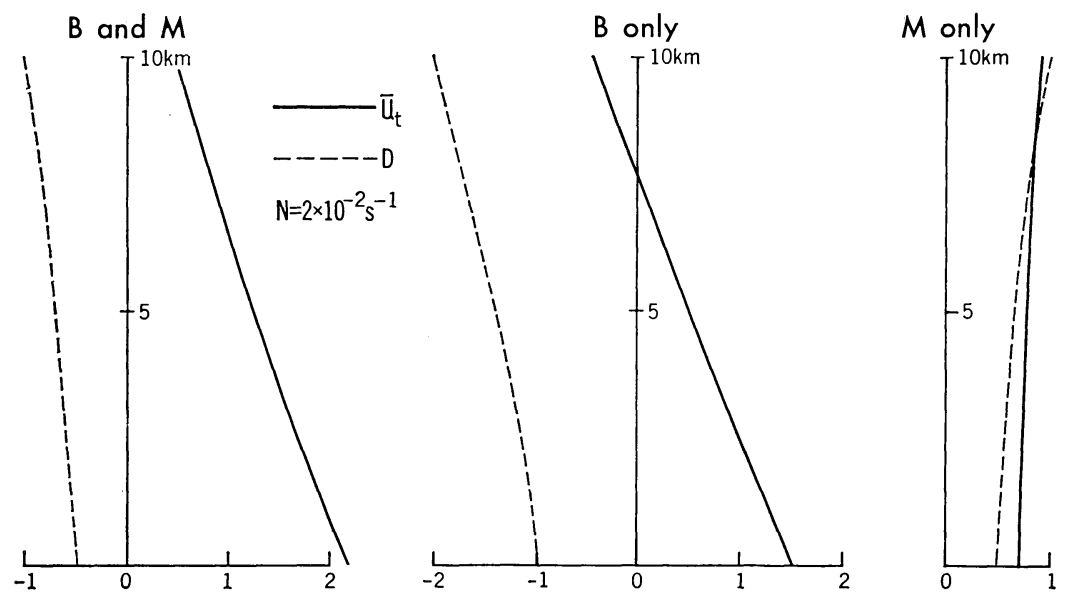

(a)
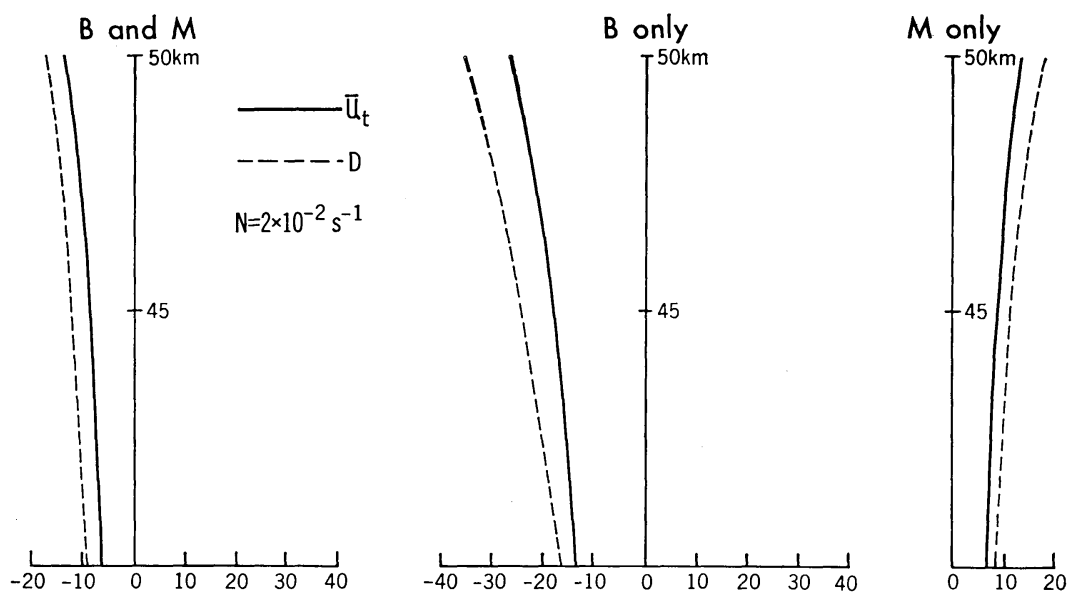

(b)

Fig. 2 As in Fig. 1 except for $N=2 \times 10^{-2} \mathrm{~s}^{-1}$. 
Table 2 As in Table 1 except for $N=2 \times 10^{-2} \mathrm{~s}^{-1}$.

\begin{tabular}{crrr}
$Z Z(\mathrm{~km})$ & $B$ and $M$ & $B$ only & $M$ only \\
\hline 50 & 3.03 & 3.07 & 3.10 \\
40 & 2.84 & 2.98 & 3.13 \\
30 & 2.19 & 2.65 & 3.26 \\
20 & 0.86 & 1.70 & 3.92 \\
10 & -0.33 & 0.28 & 13.24 \\
\hline 9 & -0.41 & 0.15 & 22.17 \\
8 & -0.48 & 0.04 & 83.13 \\
7 & -0.54 & -0.07 & -42.25 \\
6 & -0.60 & -0.17 & -16.16 \\
5 & -0.65 & -0.26 & -9.76 \\
4 & -0.69 & -0.35 & -6.88 \\
3 & -0.72 & -0.42 & -5.27 \\
2 & -0.76 & -0.49 & -4.24 \\
1 & -0.79 & -0.55 & -3.53 \\
0 & -0.82 & -0.61 & -3.02 \\
- & - & - & -
\end{tabular}

Table 2 is the same as Table 1 except for $N=2 \times 10^{-2} \mathrm{~s}^{-1}$. For this value $r_{D} /\left(f^{2} N^{-2}\right)$ is 3.1. Above $40 \mathrm{~km}, r_{u}$ is close to $r_{D}$ and larger than 1 , being consistent with the fact that $\bar{u}_{t}$ and $D$ are similar at these levels. In the troposphere, $r_{u}$ is negative. With both $B$ and $M$ and with $B$ only, $\left|r_{u}\right| /\left(f^{2} N^{-2}\right)$ is smaller than 1 , being consistent with the fact (Fig. 2a) that $\bar{u}_{t}$ and $D$ are quite different.

Fig. 3 is the same as Fig. $1 \quad\left(N=10^{-2} \mathrm{~s}^{-1}\right)$ except that the lower boundary condition is replaced by the lower boundary condition (4.9) or (4.10) for topographically forced waves. It is seen in Fig. 3a $(0-10 \mathrm{~km})$ that $D$ has the same sign as $\bar{u}_{t}$ but underestimates it. At the $40-50 \mathrm{~km}$ levels (Fig. $3 \mathrm{~b}$ ), $D$ has the same
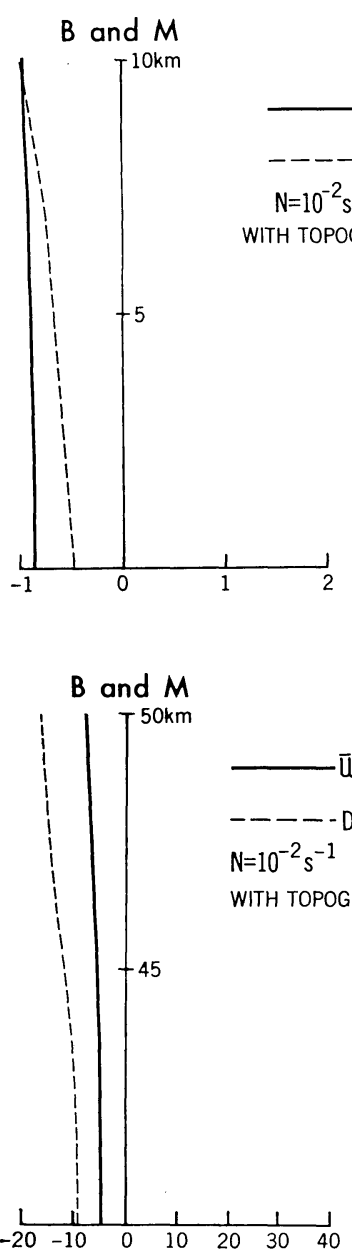

B only

$10 \mathrm{~km}$

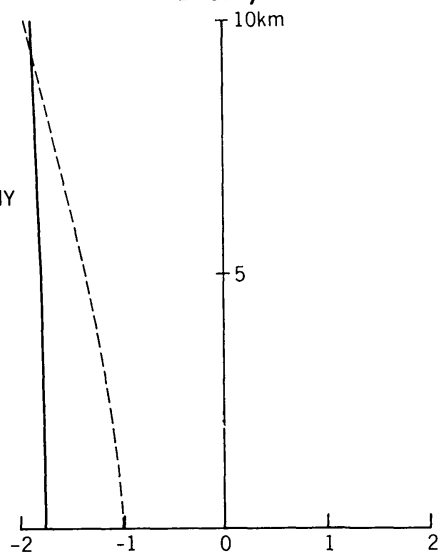

(a)
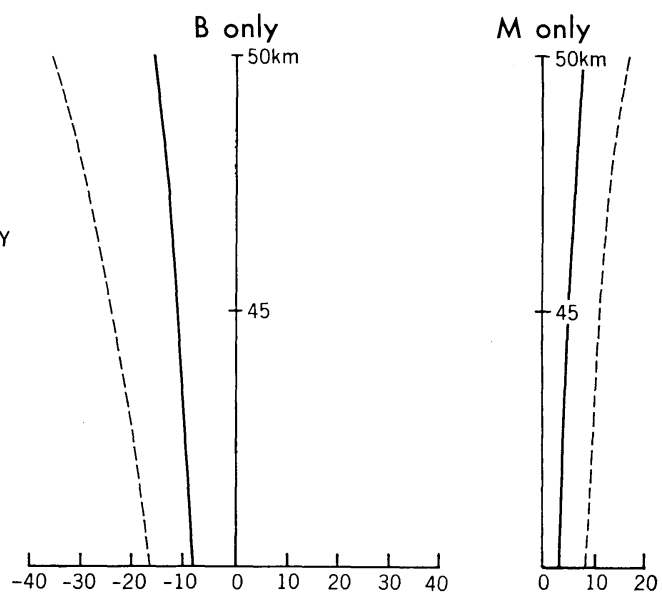

(b)

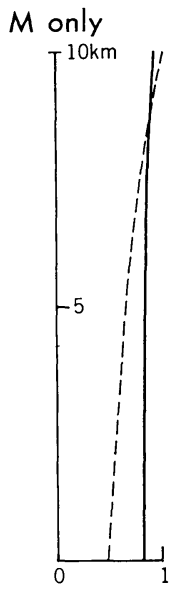


Table 3 As in Table 1 except for the topographical boundary condition.

\begin{tabular}{cccc}
\hline$Z(\mathrm{~km})$ & $B$ and $M$ & $B$ only & $M$ only \\
\hline 50 & 0.81 & 0.81 & 0.81 \\
40 & 0.87 & 0.87 & 0.87 \\
30 & 1.05 & 1.05 & 1.05 \\
20 & 1.72 & 1.72 & 1.72 \\
10 & 16.85 & 16.85 & 16.85 \\
\hline 9 & 186.14 & 186.14 & 186.14 \\
8 & -20.85 & -20.85 & -20.85 \\
7 & -9.95 & -9.95 & -9.95 \\
6 & -6.58 & -6.58 & -6.58 \\
5 & -4.95 & -4.95 & -4.95 \\
4 & -3.99 & -3.99 & -3.99 \\
3 & -3.36 & -3.36 & -3.36 \\
2 & -2.91 & -2.91 & -2.91 \\
1 & -2.58 & -2.58 & -2.58 \\
0 & -2.33 & -2.33 & -2.33 \\
\hline
\end{tabular}

sign as $\bar{u}_{t}$ but overestimates it. Fig. $3 \mathrm{~b}$ is very similar to Fig. $1 \mathrm{~b}$, since the effect of the lower boundary is negligible. When $N$ is replaced by its stratospheric value, the stratospheric acceleration (not illustrated) is very similar to Fig. $2 \mathrm{~b}$ and $\bar{u}_{t}$ is close to $D$.

Table 3 is the same as Table $1\left(N=10^{-2} \mathrm{~s}^{-1}\right)$ except for the adoption of the topographical boundary condition. Above $50 \mathrm{~km}, r_{u}$ is close to $r_{D}=0.77$. since the effect of lower boundary is negligible there. In the tropospnere $r_{u}$ becomes negative due to the lower boundary condition. However, $\left|r_{u}\right| /\left(f^{2} N^{-2}\right)$ is larger than 1 , being consistent with the fact (Fig. 3a) that $\bar{u}_{t}$ has the same sign as $D$.

\section{Effects of mean damping}

In the previous sections the effects of mean damping on wave-mean flow interaction were not considered. It is of importance to study these effects, since waves affect not only mean flows but also mean damping which, in turn, affects mean flows. In this section, simple diagnostic relations are derived to study the effects of mean damping.

When eddies are added to the steady state equilibrated without eddies, the deviation $(\Delta)$ of the zonal mean from the steady state is governed by

$$
\frac{\partial \Delta \bar{u}}{\partial t}=-\Delta M_{y}+f \Delta \bar{v}-\varepsilon \Delta \bar{u},
$$

$$
\begin{aligned}
& \frac{\partial \Delta \bar{T}}{\partial t}=-\Delta B_{y}-R_{H}^{-1} N^{2} \Delta \bar{w}-\gamma \Delta \bar{T}, \\
& \left(\rho_{0} \Delta \bar{v}\right)_{y}+\left(\rho_{0} \Delta \bar{w}\right)_{z}=0, \\
& f \Delta \bar{u}_{z}+R_{H} \Delta \bar{T}_{y}=0,
\end{aligned}
$$

and

where $\varepsilon$ and $\gamma$ are the Rayleigh and Newtonian damping coefficients, respectively. These mean dampings crudely represent diffusion and radiative damping.

In the above equations, the perturbed mean advection terms involving the deviation $(\Delta)$ are neglected. This neglection is justified in the mid-latitudes according to a quasi-geostrophic Rossby number truncation. The unperturbed mean advection terms drop out together with the other unperturbed terms, since the unperturbed terms balance each other. The unperturbed mean advection terms play an important role in the steady state tropical Hadley circulation (Schneider and Lindzen, 1977 ; Schneider, 1977), particularly when internal friction is infinitesimally small (Held and Hou, 1980).

The effect of surface friction and surface sensible heat flux can be crudely incorporated by varying $\varepsilon$ and $\gamma$ as

$$
\begin{aligned}
\varepsilon & =\varepsilon_{R} \text { for } z>z_{b} \\
& =\varepsilon_{b} \text { for } 0<z<z_{b},
\end{aligned}
$$

and

$$
\begin{aligned}
\gamma & =\gamma_{N} \text { for } z>z_{b} \\
& =\gamma_{N}+\gamma_{b} \text { for } 0<z<z_{b} .
\end{aligned}
$$

where $z_{b}$ is the depth of the surface layer and it is assumed that the temperature at the earth's surface is not affected by eddy heat flux.

By omitting the time derivatives and neglecting $\varepsilon_{R}$ as in observational diagnostics, the following steady state diagnostic relations can be obtained from (5.1)-(5.4) as explained below :

$$
\begin{aligned}
& \Delta \bar{v}(z)=f^{-1} \Delta M_{y}(z) \text { for } z>z_{b}, \\
& \Delta \bar{v}(0) \approx-z_{b}^{-1} \rho_{0}^{-1}(0) \int_{z_{b}}^{\infty} \rho_{0} \Delta \bar{v} d z, \\
& \Delta \bar{w}(z)=\rho_{0}^{-1} \int_{z}^{\infty} \rho_{0} \Delta \bar{v}_{y} d z,
\end{aligned}
$$




$$
=f^{-1} \rho_{0}^{-1} \int_{z}^{\infty} \rho_{0} \Delta M_{y y} d z \text { for } z>z_{b},
$$

$$
\begin{aligned}
\Delta \bar{u}(0) & =\varepsilon_{b}^{-1}\left\{-\Delta M_{y}(0)+f \Delta \bar{v}(0)\right\}, \\
& \approx-\varepsilon_{b}^{-1} z_{b}^{-1} \rho_{0}^{-1}(0) \int_{0}^{\infty} \rho_{0} \Delta M_{y} d z, \\
\Delta \bar{T}(0) & =-\left(\gamma_{N}+\gamma_{b}\right)^{-1} \Delta B_{y}(0), \\
\Delta \bar{T}(z) & =\gamma_{N}^{-1}\left[-\Delta B_{y}(z)-R_{H}^{-1} N^{2} \Delta \bar{w}(z)\right],
\end{aligned}
$$

and

$$
\begin{gathered}
=\gamma_{N}^{-1} R_{H}^{-1} N^{2} f^{-1} \rho_{0}^{-1} \int_{z}^{\infty} \rho_{0} \Delta D_{y} d z \\
\text { for } z>z_{b},
\end{gathered}
$$

$$
\begin{aligned}
\Delta \bar{u}(z) \approx & -f^{-1} R_{H} \int_{z_{b}}^{z} \Delta \bar{T}_{y}(z) d z \\
& -f^{-1} R_{H} \Delta \bar{T}_{y}(0) z_{b}+\Delta \bar{u}(0) .
\end{aligned}
$$

Eq. (5.7) follows from the zonal momentum balance (5.1) for $\varepsilon_{R}=0$. Eq. (5.8) is given by integrating the continuity equation (2.3) from $z=0$ to $z_{b}$ and from $z=z_{b}$ to $\infty$ with $\rho_{0} \bar{w}=0$ at $z=0$ and $\infty$. Eq. (5.9a) results by integrating the continuity equation (2.3) from $z$ to $\infty$ with $\rho_{0} \bar{w}=0$ at $z=\infty$, while $(5.9 \mathrm{~b})$ is given by inserting (5.7) into (5.9b). Eq. (5.10b) is found by inserting (5.8) into the momentum balance (5.10a). Eq. (5.11) follows from the heat balance (5.2) with $\bar{w}=0$ at $z=0$. Eq. (5.12b) is given by inserting $(5.9 \mathrm{~b})$ into the heat balance (5.12a). Eq. (5.13) results by integrating the thermal-wind balance (5.4) from 0 to $z$.

According to (5.7) the steady state $\Delta \bar{v}$ depends on $\Delta M$ only and not on $\Delta B$ in the absence of internal friction. However, the transient state $\Delta \bar{v}$ depends on both $\Delta M$ and $\Delta B$ and in turn affects $\Delta \bar{u}$. As a result, the steady state $\Delta \bar{u}$ depends on both $\Delta M$ and $\Delta B$, being consistent with the thermal wind relation (5.13) with (5.12b).

According to $(5.9 \mathrm{~b})$, the steady state indirect cell is associated with positive and negative $\Delta M_{y y}$ in the southern and northern latitudes, respectively, whereas the transient indirect cell due to $\Delta M$ occurs in the absence of mean damping when $\Delta M$ increases with height $\left(\Delta M_{z}>0\right)$ according to (3.3).
According to (5.13), $\Delta \bar{u}$ is approximately determined by $\Delta \bar{u}(0), \Delta \bar{T}_{y}(0)$ at the surface and $\Delta \bar{T}_{y}(z)$ above the surface layer. In the case of baroclinic waves, $\Delta \bar{u}(0)$ is positive and acts to increase westerlies, while $-\Delta \bar{T}_{y}(0)$ and $-\Delta \bar{T}_{y}(z)$ are negative and act to decrease the vertical shear. If $\gamma_{b}$ and $\gamma_{N}$ are sufficiently small and $\varepsilon_{b}$ is sufficiently large, the effect of $\Delta \bar{T}_{y}(0)$ and $\Delta \bar{T}_{y}(z)$ dominate the effect of $\Delta \bar{u}(0)$. Then, $\Delta \bar{u}$ can become easterly although $\bar{u}_{t}$ is westerly in the absence of mean damping. This possibility may explain why the steady state westerlies in the mid-latitude upper troposphere are reduced by including transient eddies according to Trenberth's (1973, Fig. 4, Fig. 8) numerical experiments.

The effect of eddy fluxes on $\Delta \bar{u}$ can also be interpreted in terms of acceleration as follows. The combined effect of $B$ and $M$ is to accelerate westerlies in the absence of mean damping. However, the transient state $\Delta \bar{u}$ and $\Delta \bar{T}$ affect $\bar{u}_{t}$ and $\bar{T}_{t}$ not only directly through $-\varepsilon \Delta \bar{u}$ and $-\gamma \Delta \bar{T}$ but also through $\Delta \bar{v}$ and $\Delta \bar{w}$ which are affected by the mean damping. In particular, the surface friction enhances an indirect cell due to the Ekman pumping, since the surface flow is westerly in the presence of $M$. On the other hand, the surface sensible heat flux enhances a direct cell, since this heat flux counterbalances the effect of $B$. Thus, for sufficiently strong surface friction and weak surface sensible heat flux, there is the possibility that the indirect cell becomes strong enough to overcome the effect of westerly acceleration by $-\Delta M_{y}$.

\section{Conclusions and implications}

In order to theoretically interpret the Eliassen-Palm diagnostics of wave-mean flow interaction, necessary and sufficient conditions are derived for the residual mean circulations to be negligible and the Eliassen-Palm flux divergence (EPFD) to approximate the zonal acceleration $\left(\bar{u}_{t}\right)$ in the absence of mean damping. These conditions are summarized as follows :

(1) A diagnostically necessary and sufficient condition is that the vertical-lateral scale ratio of $\bar{u}_{t}$ as defined by (3.8) is much larger than $f^{2} N^{-2}$, where $f$ and $N$ are 
the Coriolis and Brunt-Väisälä frequencies, respectively.

(2) A necessary condition is that the verticallateral scale ratio of EPFD as defined by (3.12) is much larger than $f^{3} N^{-2}$.

(3) Even if Condition (2) holds everywhere, the approximation does not necessarily hold at low levels due to the lower boundary conditions.

Condition (1) is essentially the same as the "tall mean flow condition" (Andrews and McIntyre, 1976) based on a scale analysis of a Boussinesq fluid. The present definition of the scale ratio (3.8) is more appropriate for a compressible fluid.

Condition (2) explains the large residualmean circulation associated with the sudden warming due to planetary waves with a small vertical scale of EPFD as studied theoretically by Matsuno and Nakamura (1979).

Condition (3) may explain why the heat flux of thermally forced stationary planetary waves results in larger residual circulations than the eddy induced circulations in the troposphere, whereas that of topographically forced waves results in much smaller residual circulations than the eddy-induced circulations as studied theoretically by Trenberth (1983, Fig. 14, Fig. 13). Under the topographial lower boundary condition, an eddy heat flux results in less residual circulations than under the non-topographical condition as demonstrated by the present analytical model.

It is shown by a simple analytical model that a violation of Condition (1) due to the effect of the lower boundary conditions may explain why some observational diagnostic studies indicate that transient eddies accelerate westerlies in the mid-latitude upper troposphere, although the transient EPFD is easterly there. For Eady and Charney baroclinic wave (see Appendix D), however, easterlies are accelerated in the upper layer, since the eddy momentum flux vanishes for these waves.

It is shown by simple diagnostic relations that the steady state upper tropospheric westerlies can be either enhanced or reduced in the presence of mean damping and mean radiative heating by adding transient waves, although these waves accelerate westerlies in the absence of mean damping. The reduction can occur when waves accelerate the surface westerlies and, in turn, enhance frictionally induced indirect mean circulations which decelerate the upper westerlies due to the Coriolis effect. This may explain the result of the numerical experiments of Trenberth (1973) and Taylor (1980). On the other hand, a recent diagnostic model of Schneider (1984, p. 1107) indicates that the steady state upper tropospheric westerlies are enhanced by the combined effects of eddy momentum and heat fluxes. Since these results can be sensitive to the model resolutions, radiative heating, surface sensible heat flux and surface drag, the effects of transient waves on the zonal wind should be re-examined by the use of realistic general circulation models. According to the preliminary results of experiments with a current GFDL general circulation model, the winter tropospheric jet is shifted equatorward in the absence of transient waves being qualitatively consistent with the eddy momentum flux convergence and divergence, while the spring tropospheric jet is increased in situ being qualitatively consistent with the EPFD. These results will be reported in detail elsewhere.

\section{Acknowledgements}

The author is very grateful to Dr. S. Manabe for his advice and to Drs. I.M. Held, S. Miyahara, J. D. Mahlman, and K.E. Trenberth for their valuable comments on the original manuscript. Thanks are extended to Ms. J. Kennedy for her excellent typing.

\section{Appendix A}

List of symbols

$y$ northward distance

$z$ vertical "log pressure" coordinate $\left[\equiv-H \ln \left(p / p_{s}\right)\right]$

$t$ time

$u$ eastward velocity

$v$ northward velocity

$w$ "vertical velocity" in log pressure coordinates $[\equiv d z / d t]$

$\rho_{0} \dot{\psi}$ mass stream function of meridional circulation

$T$ departure of temperature from $T_{o}$ 
To $(z)$ basic state temperature

$Q$ heating rate per unit mass

$\phi$ departure of geopotential from basic state

$p$ pressure

$\rho_{0}(z)$ basic state density

$M$ northward eddy momentum flux

$B$ northward eddy heat flux

$D$ Eliassen-Palm flux divergence

$H$ constant scale height

$h$ equivalent depth

$h_{R} \quad$ Rossby depth

$R$ gas constant for dry air $\left[=287 \mathrm{~m}^{2} \mathrm{~s}^{-2} \mathrm{k}^{-1}\right]$

$R_{H} \quad$ gas constant divided by $H[\equiv R / H]$

$c_{p}$ specific heat at constant pressure

$g$ gravitational acceleration $\left[=9.8 \mathrm{~m} \mathrm{~s}^{-1}\right]$

$f$ constant Coriolis parameter

$N$ constant Brunt-Väisälä frequency

$l$ meridional wavenumber of eddy flux

$m$ vertical decaying constant of eddy flux

$\mu$ vertical decaying constant of homogeneous solution

$r_{u}$ vertical-lateral scale ratio of mean flow acceleration

$r_{D}$ vertical-lateral scale ratio of $D$

$\varepsilon$ Rayleigh friction coefficient

$\gamma$ Newtonian cooling coefficient

\section{Appendix B}

Boundary conditions

The lower boundary condition for Eulerianmean flow in the presence of topography and in the absence of mean Ekman pumping is given (Charney and Drazin, 1961; Andrews, 1980) by

$$
\bar{w} \approx g R_{H}^{-1} T_{0}^{-1}\left(\overline{v^{\prime} h^{\prime}}\right)_{y},
$$

where $h$ is the topographic height.

In the absence of heating and Ekman pumping in stationary waves, $\overline{v^{\prime} h^{\prime}}$ is reduced to

$$
\overline{v^{\prime} h^{\prime}}=-R_{H} N^{-2} B \text {. }
$$

The condition (B.1) is more rigorously written in terms of the vertical velocity $\left(g^{-1}\left(d \phi / d^{t}\right)\right)$ instead of $W$ as

$$
\bar{\phi}_{t}+R_{H} T_{0} \bar{w}=g\left(\overline{v^{\prime} h^{\prime}}\right)_{y} .
$$

This condition is reduced to

$$
\begin{aligned}
& f^{2} \rho_{0}^{-1}\left(\rho_{0} \bar{\psi}\right)_{z}+R T_{0} \bar{\psi}_{y y} \\
= & -f M_{y}+g\left(\overline{v^{\prime} h^{\prime}}\right)_{y y} \text { at } z=0 .
\end{aligned}
$$

It should be noted that (B.3) is reduced to (B.1) when the time derivative is negligible.

\section{Appendix C}

The Green's function

The solution to (3.1) for imposed $D$ with arbitrary vertical structure and sinusoidal lateral structure is given by

$$
\begin{aligned}
\bar{u}_{t}:= & \int_{0}^{\infty} G\left(z-z^{\prime}\right) D_{y y} d z^{\prime}+C_{0} \exp (-\mu z) \\
& \cdot \exp (z / H) \sin (l y)
\end{aligned}
$$

where $G$ is the Green's function for an infinite vertical domain given by

$$
\begin{aligned}
& G(z)=G(0) \exp (-\mu z) \exp (z / H), \quad z>0 \\
& =G(0) \exp (\mu z), \quad z<0,
\end{aligned}
$$

with $\mu$ defined by (4.16a).

$C_{0}$ in (C.1) is determined by the lower boundary condition (4.8) and depends on $D(z)$ and $B(0)$.

It should be noted that $\bar{u}_{t}$ depends on $D(z)$ and $B(0)$ but does not explicitly depend on $M(z)$, although $\bar{u}_{t}$ implicitly depends on $M(z)$ through $D(z)$. The Green's function $G(z)$ behaves like a delta function relative to the vertical profile of $D$ for sufficiently large $\mu$ and sufficiently large vertical scale of $D$. In this case, $\bar{u}_{t}$ is approximated by $D$ at a sufficiently large height where the second term in (C.1) is negligible, being consistent with the necessary condition (3.12).

\section{Appendix D}

Mean circulations induced by Eady and Charney baroclinic waves

Baroclinically unstable waves studied by Eady (1949) and those by Charney (1947) are associated with poleward heat fluxes and zero momentum fluxes. The essential differences between these two waves are the absence of the beta effect, compressibility and the presence of a lid in the Eady wave. The eddy heat flux and E-P flux are vertically constant for the Eady wave, while these fluxes decrease 


\section{EULERIAN-MEAN CIRCULATIONS}
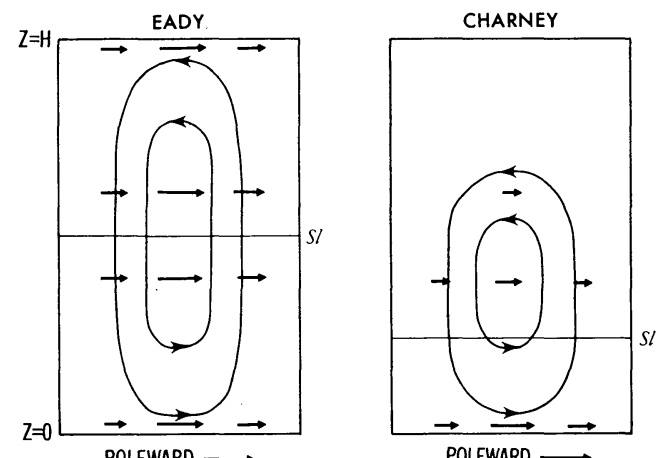

Fig. 4a Schematic latitude-height sections of eddy heat flux (vectors) and Eulerian-mean circulations (contours) for an Eady wave (left) and a Charney wave (right) in a channel. Steering levels are marked $s l$.

\section{RESIDUAL-MEAN CIRCULATIONS}
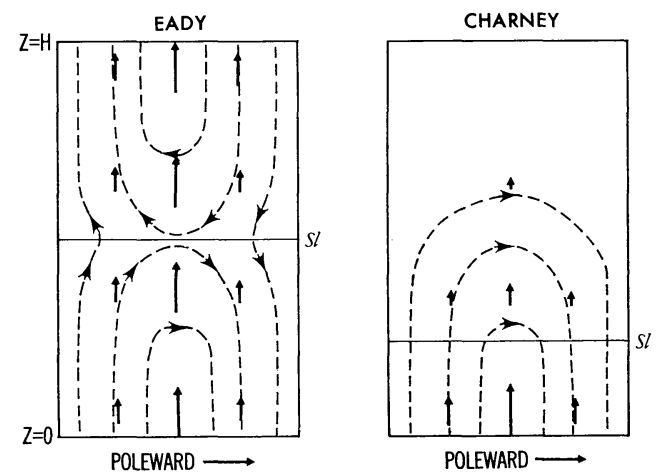

Fig. 4b Schematic latitude-height sections of E-P fluxes (vectors) and residual circulations (contours) for an Eady wave (left) and a Charney wave (right) in a channel. Steering levels are marked $s l$. This picture is partly based on Edmon et al. (1980, Fig. 2) and Hoskins (1982, Fig. 7.3).

with height for the Charney wave. As illustrated schematically by Fig. 4a, the eddy heat fluxes induce indirect cells which in turn accelerate westerlies and easterlies in the lower and upper layers, respectively.

Fig. 4b shows schematically that the residual circulations for the Eady wave consist of direct and indirect circulations in the lower and upper layers (see Kanzawa, 1984a, p. 42 for the analytical solution). The vertical velocity (2.14) at the lower and upper boundaries is consistent with the poleward eddy heat fluxes. The mean Coriolis force due to these residual circulations accelerates westerlies and easterlies in the lower and upper layers, while the E-P flux divergence vanishes everywhere. These residual circulations resemble the Lagrangian-mean circulations induced by the growing Eady wave as studied by Uryu (1979, Fig. 2c).

In the case of the Charney wave, the E-P flux divergence $(D)$ forces easterlies, while the residual circulations force westerlies at all the levels. The residual circulations dominate $D$ and forces westerlies in the lower layer, while $D$ dominates the residual circulation and forces easteries in the upper layer. The results based on the Charney wave are similar to those (Fig. 1a) of the present model with a non-topographical boundary condition in the absence of an eddy momentum flux.

\section{References}

Andrews, D. G., 1980: On the mean motion induced by transient inertio-gravity waves. Pure Appl. Geophys., 118, 177-188.

_ and M.E. McIntyre, 1976: Planetary waves in horizontal and vertical shear: The generalized Eliassen-Palm relation and the mean zonal acceleration. J. Atmos. Sci., 33, 2031-2048.

- and $-1978 \mathrm{a}$ : Generalized Eliassen-

Palm and Charney-Drazin theorems for waves on axisymmetric mean flows in compressible atmospheres. J. Atmos. Sci., 35, 175-185.

- and - 1978b: An exact theory of nonlinear waves on a Lagrangian-mean flow. $J$. Fluid Mech., 89, 609-646.

$\longrightarrow$ and $-1978 \mathrm{c}$ : On wave-action and its relatives. J. Fluid Mech., 89, 647-664.

- J. D. Mahlman, and R. W. Sinclair, 1983 : Eliassen-Palm diagnostics of wave-mean flow interaction in the GFDL "SKYHI" general circulation model. J. Atmos. Sci., 40, 2768-2784.

Boyd, J.P. 1976: The noninteraction of waves with the zonally averaged flow on a spherical earth and the interrelationships of eddy fluxes of energy, heat and momentum. J. Aimos. Sci., 33, 2285-2291.

Bretherton, F.P., 1969: Momentum transport by gravity waves. Quart. J. Roy Meteor, Soc., 95, 213-243.

Butchart, N., S. A. Clough, T. N. Palmer and P. J. Trevelyan, 1982: Simulations of an observed stratospheric warming with quasi-geostrophic refractive index as a model diagnostic. Quart. J. R. Met. Scc., 108, 475-502.

Charney, J. G., 1947 : The dynamics of long waves. 
in a baroclinic westerly current. J. Meteor., 4, 135-163.

- and P. G. Drazin, 1961: Propagation of planetary-scale disturbances from the lower into the upper atmosphere. J. Geophys. Res., 66, 83109.

Crawford, S. L. and T. Sasamori, 1981: A study of the sensitivity of the winter mean meridional circulation to sources of heat and momentum. Tellus, 33, 340-350.

Dickinson, R. D., 1969: Theory of planetary wavezonal flow interaction. J. Atmos. Sci., 26, 73-81.

Dunkerton, T. J., 1980: A Lagrangian mean theory of wave, mean-flow interaction with applications to nonacceleration and its breakdown. Rev. Geophys. and Space Phys., 18, 387-400.

- C.-P.F. Hsu and M.E. McIntyre, 1981: Some Eulerian and Lagrangian diagnostics for a model stratospheric warming. J. Atmos. Sci., 38, 819-843.

Eady, E. T., 1949: Long waves and cyclone waves. Tellus, 1, 33-52.

Edmon, H. J., Jr., B. J. Hoskins and M. E. McIntyre, 1980: Eliassen-Palm cross sections for the troposphere. J. Atmos. Sci., 37, 2600-2616. (see also Corrigendum, J. Atmos. Sci., 38, 1115)

Eliassen, A., 1952: Slow thermally or frictionally controlled meridional circulation in a circular vortex. Astrophys. Norv., 5, 19-60.

- and E. Palm, 1960: On the transfer of energy in stationary mountain waves. Geophys. Publ., 22, 1-23.

Geller, M. A., M.-F. Wu, M.E. Gelman, 1983: Troposphere-stratosphere (surface-55 km) monthly winter general circulation statistics for the Northern Hemisphere-four year averages. J. Atmos. Sci., 40, 1334-1352.

Gille, J.C. and L. V. Lyjak, 1984: An overview of wave-mean flow interactions during the winter of 1978-79 derived from LIMS observations. Dynamics of the Middle Atmosphere, 289-306, Terra Scientific Publishing Company, Tokyo.

Hartmann, D. L., C. R. Mechoso and K. Yamazaki, 1984: Observations of wave-mean flow interaction in the Southern Hemisphere. J. Atmos. Sci., 41, 351-362.

Hayashi, Y., 1970: A theory of large-scale equatorial waves generated by condensation heat and accelerating the zonal wind. Meteor. Soc., Japan, 48, 140-160.

- 1985: Theoretical interpretations of the Eliassen-Palm diagnostics of wave-mean flow interaction, Part II. Effects of mean damping. $J$. Meteor. Soc. Japan, 63, 513-521.

Held, I. M. and A. Y. Hou, 1980: Nonlinear axially symmetric circulations in a nearly inviscid atmosphere. J. Atmos. Sci., 37, 515-533.

Holton, J.R., 1974: Forcing of mean flows by stationary waves. J. Atmos. Sci., 31, 942-945.
, 1975: The dynamic meteorology of the stratosphere and mesosphere. Meteor. Monogr., No. 37, Amer. Meteor. Soc., 218 pp.

, 1980: Wave propagation and transport in the middle atmosphere. Phil. Tran. Roy. Soc. London, A296, 73-85.

__ and R.S. Lindzen, 1972: An updated theory for the quasi-biennial cycle of the tropical stratosphere. J. Atmos. Sci., 29, 1076-1080.

Hoskins, B. J., 1982: Modelling of the transient eddies and their feedback on the mean flow. In Large-Scale Dynamical Processes in the Atmosphere, R.P. Pearce and B. J. Hoskins, Eds., Academic Press.

- I. N. James and G. H. White, 1983: The shape, propagation and mean-flow interaction of large-scale weather systems. J. Atmos. Sci., 40, 1595-1612.

Kanzawa, H., 1982: Eliassen-Palm flux diagnostics and the effect of the mean wind on planetary wave propagation for an observed sudden stratospheric warming. J. Meteor. Soc. Japan, 60, 1063-1073.

_- 1984a: Quasi-geostrophic energetics based on a transformed Eulerian equation with application to wave-zonal flow interaction problem. $J$. Meteor. Soc. Japan, 62, 36-51.

, 1984b: Four observed sudden warmings diagnosed by the Eliassen-Palm flux and refractive index. Dynamics of the Middle Atmosphere, 307-331, Terra Scientific Publishihng Company, Tokyo.

Karoly, D. J., 1982: Atmospheric vacillations in a general circulation model III: Analysis using transformed Eulerian-mean diagnostics. J. Atmos. Sci., 39, 2916-2922.

Kuo, H.-L., 1956: Forced and free meridional circulations in the atmosphere. J. Atmos. Sci., 13, 561-568.

Lau, N.C. and E. O. Holopainen, 1984: Transient eddy forcing of the time-mean flow as identified by quasi-geostrophic tendencies. J. Atmos. Sci., 41, 313-328.

Lindzen, R.S., 1970: Vertical momentum transport by large-scale disturbances of the equatorial lower stratosphere. J. Meteor. Soc. Japan, 48, 81-82.

Lorenz, E. N., 1967 : The Nature and Theory of the General Circulation in the Atmosphere. WMO Publ. No. 218, 161 pp.

- 1969: The nature of the global circulation of the atmosphere: a present view. The Global Circulation of the Atmosphere. Roy. Meteor. Soc. Edited by G. A. Corby, $257 \mathrm{pp}$.

Mahlman, J. D. and L. J. Umscheid, 1984 : Dynamics of the middle atmosphere : success and problems of the GFDL "SKYHI" general circulation model. Dynamics of the Middle Atmosphere, Advances in Earth and Planetary Sciences, 501-525. Terra Scientific Publishing Company, Tokyo. 
Matsuno, T., 1971: A dynamical model of the stratospheric sudden warming. J. Atmos. Sci., 28, 1479-1494.

- 1980: Lagrangian motion of air parcels in the stratosphere in the presence of planetary waves. Pageoph., 118, 189-216.

- and K. Nakamura, 1979: The Eulerianand Lagrangian-mean meridional circulations in the stratosphere at the time of a sudden warming. J. Atmos. Sci., 36, 640-654.

McIntyre, M.E., 1980: An introduction to the generalized Lagrangian-mean description of wave, mean flow interaction. Pageoph., 118, 152-176.

- 1981: On the 'wave momentum' myth. J. Fluid Mech., 106, 331-347.

Nakamura, K., 1979: A generalization of "EliassenPalm relation." J. Meteor. Soc. Japan, 57, 215226.

O'Neill, A. and C. E. Youngblut, 1982: Stratospheric warmings diagnosed by the transformed Eulerianmean equations and the effect of the mean state on wave propagation. J. Atmos. Sci., 39, 13701386.

Palmer, T. N., 1981a: Diagnostic study of a wavenumber-2 stratospheric sudden warming in a transformed Eulerian-mean formalism. J. Atmos. Sci., 38, 844-855.

- 1981b: Aspects of stratospheric sudden warming studied from a transformed Eulerianmean view point. J. Geophys. Res., 86, 96799687.

-, 1982: Properties of the Eliassen-Palm flux for planetary scale motions. J. Atmos. Sci., 39, 992-997.

Pfeffer, R.L., 1981: Wave-mean flow interactions in the atmosphere. J. Atmos. Sci., 38, 13401359.

Phillips, N. A., 1954 : Energy transformations and meridional circulations associated with simple baroclinic waves in a two-level, quasi-geostrophic model. Tellus, 3, 273-286.

Plumb, R. A., 1983: A new look at the energy cycle. J. Atmos. Sci., 40, 1669-1688.

, 1985: On the three-dimensional propagation of stationary waves. J. Atmos. Sci., 42, 217-229.

- and R.C. Bell, 1982 : Equatorial waves in a steady zonal shear flow. Quart. J.R. Met. Soc., 108, 313-334.

Salustri, G. and P. H. Stone, 1983: A diagnostic study of the forcing of the Ferrel cell by eddies, with latent heat included. J. Atmos. Sci., 40,
1101-1109.

Sato, Y., 1980: Observational estimates of Eliassen and Palm flux due to quasi-stationary planetary waves. J. Meteor. Soc. Japan, 58, 430-435.

Sawada, R. and A. Matsushima, 1964: Thermally driven annual atmospheric oscillations as a cause of dynamic heating of the winter polar mesosphere. J. Met. Soc. Japan, 42, 97-108.

Schneider, E. K., 1977: Axially symmetric steadystate models of the basic state for instability and climate studies. Part II. Nonlinear calculations. J. Atmos. Sci., 34, 280-296.

, 1984: Response of the annual and zonal mean winds and temperatures to variations in the heat and momentum sources. J. Atmos. Sci., 41, 1093-1115.

and R.S. Lindzen, 1977: Axially symmetric steady-state models of the basic state for instability and climate studies. Part I. Linearized calculations. J. Atmos. Sci., 34, 263-279.

Shepherd, T.G., 1983: Mean motions induced by baroclinic instability in a jet. Geophys. Astrophys. Fluid Dynamics, 27, 35-72.

Stone, P. H. and G. Salustri, 1984: Generalization of the quasi-geostrophic Eliassen-Palm flux to include eddy forcing of condensation heating. $J$. Atmos. Sci., 41, 3527-3536.

Taylor, K.E., 1980: The roles of mean meridional motions and large-scale eddies in zonally averaged circulations. J. Atmos. Sci., 37, 1-19.

Trenberth, K.E., 1973: Global model of the general circulation of the atmosphere below 75 kilometers with an annual heating cycle. Mon. Wea. Rev., 101, 287-307.

- 1983 : Interactions between orographically and thermally forced planetary waves. J. Atmos. Sci., 40, 1126-1153.

Uryu, M., 1979: Lagrangian-mean motion induced by a growing baroclinic wave. J. Meteor. Soc. Japan, 57, 1-20.

- 1980: Acceleration of mean zonal flows by planetary waves. Pure Appl. Geophys., 118, 661-693.

Vernekar, A.D., 1967 : On mean meridional circulations in the atmosphere. Mon. Wea. Rev., 95, 705-721.

Wiin-Nielsen, A. and J. Sela, 1971: On the transport of quasi-geostrophic potential vorticity. Mon. Wea. Rev., 99, 447-459.

and A.D. Vernekar, 1967 : On the influence of the mean meridional circulation on the zonal flow. Mon. Wea. Rev., 95, 723-732. 


\section{波動一平均流相互作用の Eliassen-Palm 解析についての理論的解勫}

\section{第 1 部：地表境界条件の効果}

林 良一

Geophysical Fluid Dynamics Laboratory/NOAA

波動一平均流相互作用の Eliassen-Palm 解析についての理論的解釈を行った。

Mean damping のない場合, Eliassen-Palm flux divergence (EPFD) が平均流加速の近似となるための 必要十分条件を導いた。地表境界条件の影響のためにこの必要十分条件が成立しなくなる可能性を簡単な理論 的モデルで示し, 実際の中緯度上部対流圈の観測では非定常波に伴う EPFD は東風加速の倾们を持つにもか かわらず，非定常波は西風を加速する理由を示した。

Mean damping や radiative heating の大きさによって，上部対流圈定常状態の西風は非定常波動により 強められたり弱められたりする可能性がある事を簢単な関係式で示した。 